\title{
State-of-the-Art Review on Operational Resilience: Concept, Scope and Gaps
}

\author{
Seyoum Eshetu Birkie ${ }^{1,2, *}$, Paolo Trucco ${ }^{1}$, and Matti Kaulio ${ }^{2}$ \\ ${ }^{1}$ Management, Economics and Industrial Engineering Department, Politecnico di Milano, Italy \\ Seyoum.birkie@mail.polimi.it, paolo.trucco@polimi.it \\ ${ }^{2}$ Department of Industrial Economics and Management, \\ Royal Institute of Technology, Sweden \\ mkaulio@ug.kth.se
}

\begin{abstract}
This state-of-the-art review analyses literature on resilience paradigm perspectives and conceptualizations in business and management. Attempts have been made to produce a definition that reflects on and attempts to resolve inconsistencies and pursue with the conception of operational resilience. Future research directions are indicated by arguing on the possible relationships among operational resilience and modern operations management paradigms like lean thinking in view of operational performance.
\end{abstract}

Keywords: resilience, operational resilience, operational risk, operational performance, state-of-the-art.

\section{Introduction}

The uncertainty of business environments and complexity of risks has increased much more than ever before. Literatures present attempts to understand and utilize the resilience paradigm for improving decisions for business success departing from antecedent paradigms and practices in the face of uncertainties and turbulences [1], [2].

To mention an incident, in 2002, the 29 West Coast ports in USA were closed for around ten days due to longshoremen's strike. Firms in different sectors were left with delayed incoming supplies and outgoing deliveries for the Christmas sales. Dell, being one of the firms faced with the situation, was able to outperform competition using its internal capabilities to re-arrange product configurations and make early deals with airfreight service providers to re-secure deliveries [3]. Resilience has to do with features in business firms to be ready for such unforeseen (mis-)fortunes and respond fast in the intent of reducing unwanted influences. There are several similar examples in publications mentioned in this paper and elsewhere (e.g. [2], [4]).

The resilience concept has been in use in different knowledge domains (e.g. psychology, ecology, engineering) for decades [5-7]. Its use in business and management studies (dominantly in supply chain management) boosted post 9/11 [2], and the

\footnotetext{
* Corresponding author.
} 
global financial crisis in 2008 as evidenced by large number of articles published, and still growing, in the field. Resilience has been conceptualized differently in different disciplines [5], [8]. It could be argued that the differences in the definitions of the concept are partly influenced by the research knowledge area and applicability specifics; but there are concerns that the term is in danger of becoming "vacuous buzzword" due to usage without consensus in meaning and concept [9].

Accordingly, one of our objectives in this review is to understand what has been done to-date and propose a conceptual definition in an attempt to reduce prevailing inconsistencies by identifying relevant core elements that operational resilience constitutes. By pursuing with this, we also intend to reflect on reviewed literature and pinpoint some gaps for future research about operational resilience.

\section{Methodology}

The approach we followed is as follows. First some general literature bearing the topic of resilience (in domains of ecological studies, engineering, psychology sociology, risk management and other business related areas) is studied to identify the important reference publications, resilience definitions and descriptive explanations. To aid our focus in operational resilience in business firms, we performed a keyword search of publications (books, chapters, journal articles, chapters, proceedings, reports) using the logical combination of relevant keywords (see appendix for detail). The search has been limited to publication sources related to management, business, risk and decision science related studies. Web of Knowledge, Scopus, and Google Scholar served as primary search aids.

Abstracts (and when necessary full paper) of publications have been scanned to shortlist relevant papers in line with our objectives and scope. Some interesting publications are also identified from the reference list of shortlisted papers and included in the review. For publications which are extended forms of previously published literature by the same author(s) and when they do not appear to bear significantly different contributions for our objectives and scope, only the version that appeared more comprehensive is considered.

The findings and brief discussion are presented in succeeding sections. First we start with synthesizing core aspects of resilience from literature from which we propose an operational resilience definition. We jointly discuss how different perspectives of resilience in business contribute to operational resilience. We finally discuss issues that extend beyond definitions to pinpoint gaps for future research.

\section{Discussion: The Review}

In business environments, uncertainties are not only unavoidable but also getting more and more complicated [2], [10]. Such dynamism made business decisions more difficult than ever before. An important challenge in dealing with risks and uncertainties through resilience is the inconsistency of conceptual understanding of resilience in publications, which may also affect how business practitioners perceive it. Some 
scholars also argue that resilience concepts related to it (vulnerability, risk and robustness) also lack formal conception apart from verbal definition (e.g. [11]). We therefore assumed reviewing different definitions as well as perspectives or lines of descent for operational resilience would be helpful.

A recent literature review on resilience by Bhamra and others [12] summarizes findings from literature on resilience studies considering three main aspects: perspectives, concepts, and research methodologies used. Accordingly, resilience perspectives were viewed as ecological, individual, socio-ecological/community, organizational, and supply chain. They classified concepts into aspects like strategy, performance and capabilities. They also present list of resilience definitions and brief descriptions. We take this a step further to plot such definitions in several resilience papers to extract relevant aspects to construct a definition for operational resilience.

\subsection{Definitions: The Synthesis}

In the field of ecological studies, a typical resilience definition given by Holling in 1973 is referred by many articles including those outside the ecological domain (e.g. [5], [6], [13], [14]). It states resilience as "a measure of the persistence of systems and of their ability to absorb change and disturbance and still maintain the same relationships between populations or state variables" ([15], p. 14).

In engineering, resilience is defined as the physical property of a material that can return to its original shape (state or position) after deformation that does not exceed its elastic limits (e.g. [6]).

In a broader sense, definitions and conceptions of resilience in different domains seem to agree that: unanticipated changes (disorders) occur following some triggering event ([2], [4], [13]) which influence entities (individuals, physical or ecological systems, business enterprises or organizations) to go through some state change. Entity could mean. The entities may possess internal capabilities of coping (with limit) shaped by interaction with the environments. Resilience papers in ecosystem studies regard change (disorder) solely from causes "external" to entities whereas "internal" causes of disruptive events appear equally important in operational resilience. Some papers in business related resilience (e.g. [5], [9], [16]) capture multiple response modes when faced with (disruptive) uncertainties. A few of them (especially those on operational resilience) additionally recognize the opportunity (upside) of risk as well as the threats (downside) that are possible consequences of unanticipated pressures and changes (e. g. [8], [17-19]).

We argue that the definitions (category I of table 1) and descriptive discussions for papers providing no verbal definitions (category II of table 1) of resilience in business firms can be seen in view of five broad aspects or phases: sense, build, adapt/reconfigure, sustain, and recover/enhance.

Sense. Because the focus of resilience is mainly to deal with unanticipated changes and pressures in the business environments, this aspect is related to how firms try to improve visibility of indicators and proxies for detecting influential changes and/or their potential influences yet to come [7]. A common term used in several papers is "situation awareness" (e. g. [8]). 
Build. Different literature in resilience discuss about resisting influence of (for example disruptive) changes ([13]) and coping mechanisms or mitigations ([20]). Building proper capabilities inherently or acquiring them from somewhere depending on vulnerability levels is essential for both of these.

Table 1. Literature sources of resilience concept, definition and relevant aspects

\begin{tabular}{|c|c|c|c|c|c|c|c|c|c|}
\hline \multirow[b]{2}{*}{ Year } & \multirow[b]{2}{*}{$\begin{array}{l}\text { Sources of resilience } \\
\text { concept } \\
\text { (author(s), [citation]) }\end{array}$} & \multicolumn{5}{|c|}{ Core aspects } & \multicolumn{2}{|c|}{ Breadth } & \multirow[b]{2}{*}{ 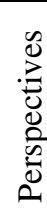 } \\
\hline & & $\begin{array}{l}\mathscr{\infty} \\
\stackrel{0}{0} \\
\mathscr{\infty}\end{array}$ & $\stackrel{\overrightarrow{0}}{\vec{\theta}}$ & 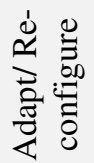 & 节 & 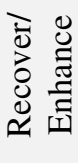 & 苞 & 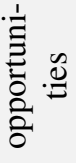 & \\
\hline
\end{tabular}

\section{Category I: Definition based}

\begin{tabular}{|c|c|c|c|c|c|c|c|c|c|}
\hline & & \multirow[b]{2}{*}{$X$} & \multirow{3}{*}{$\begin{array}{l}X \\
X\end{array}$} & \multirow{2}{*}{\multicolumn{2}{|c|}{$\mathrm{X}$}} & \multirow{2}{*}{\multicolumn{2}{|c|}{$X$}} & \multirow[b]{2}{*}{-} \\
\hline 1973 & Holling [15] & & & & & & & & \\
\hline 2000 & Frost et al. * [18] & & & & $\mathrm{X}$ & $X$ & $\mathrm{X}$ & & GC \\
\hline 2003 & Hamel \& Välikangas [19] & & $\mathrm{X}$ & $\mathrm{X}$ & & & $\mathrm{X}$ & $\mathrm{X}$ & $\mathrm{SO}$ \\
\hline 2004 & Christopher \& Peck [2] & & $\mathrm{X}$ & $X$ & & $X$ & $\mathrm{X}$ & & $\mathrm{SC}$ \\
\hline 2004 & Walker et al [6] & & $\mathrm{X}$ & $\mathrm{X}$ & $X$ & $X$ & $\mathrm{X}$ & & - \\
\hline 2006 & Caralli $*[21]$ & & $X$ & $\mathrm{X}$ & $\mathrm{X}$ & $\mathrm{X}$ & $\mathrm{X}$ & $\mathrm{X}$ & $\mathrm{BC}, \mathrm{GC}$ \\
\hline 2006 & Oh \& Teo * [7] & $X$ & $\mathrm{X}$ & $X$ & $X$ & & $\mathrm{X}$ & & $\mathrm{SO}$ \\
\hline 2007 & Rose [9] & & $X$ & $X$ & & $X$ & $\mathrm{X}$ & & - \\
\hline 2007 & Sheffi [4] & & $\mathrm{X}$ & $\mathrm{X}$ & & $\mathrm{X}$ & $\mathrm{X}$ & & $\mathrm{SC}$ \\
\hline 2008 & Falasca et al. [22] & $\mathrm{X}$ & $\mathrm{X}$ & $\mathrm{X}$ & & $\mathrm{X}$ & $\mathrm{X}$ & & $\mathrm{SC}$ \\
\hline 2008 & Stolker et al. * [23] & $\mathrm{X}$ & $\mathrm{X}$ & $\mathrm{X}$ & $X$ & $\mathrm{X}$ & $\mathrm{X}$ & & $\mathrm{SC}$ \\
\hline 2009 & $\begin{array}{l}\text { Ponomarov \& Holcomb } \\
\text { [5] }\end{array}$ & $\mathrm{X}$ & $X$ & $X$ & $X$ & $X$ & $X$ & & $\mathrm{SC}$ \\
\hline 2010 & Välikangas [17] & $\mathrm{X}$ & $\mathrm{X}$ & $X$ & $X$ & $\mathrm{X}$ & $\mathrm{X}$ & $\mathrm{X}$ & $\mathrm{SO}$ \\
\hline 2012 & Scholz et al. [11] & $\mathrm{X}$ & $\mathrm{X}$ & $\mathrm{X}$ & & $\mathrm{X}$ & $\mathrm{X}$ & & - \\
\hline \multicolumn{2}{|c|}{ Category II: Description based } & \multirow{3}{*}{$\mathrm{X}$} & & & & & & \multirow{10}{*}{$\mathrm{X}$} & \\
\hline 2005 & Sheffi \& Rice $[1]$ & & $\mathrm{X}$ & $\mathrm{X}$ & $X$ & $\mathrm{X}$ & $\mathrm{X}$ & & $\mathrm{SC}, \mathrm{SO}$ \\
\hline 2006 & Allen et al.* [18] & & $\mathrm{X}$ & $\mathrm{X}$ & $\mathrm{X}$ & $\mathrm{X}$ & $X$ & & $\mathrm{SC}$ \\
\hline 2007 & Craighead et al. [20] & $X$ & $\mathrm{X}$ & $\mathrm{X}$ & & $\mathrm{X}$ & $\mathrm{X}$ & & $\mathrm{BC}, \mathrm{SC}$ \\
\hline 2007 & McManus et al. [8] & $\mathrm{X}$ & $\mathrm{X}$ & $X$ & $X$ & & $\mathrm{X}$ & & $\mathrm{SO}$ \\
\hline 2007 & Waters [10] & $\mathrm{X}$ & $\mathrm{X}$ & $\mathrm{X}$ & & $X$ & $\mathrm{X}$ & & $\mathrm{SC}$ \\
\hline 2010 & Melnyk et al. [24] & $\mathrm{X}$ & $\mathrm{X}$ & $X$ & $X$ & $\mathrm{X}$ & $\mathrm{X}$ & & $\mathrm{SC}$ \\
\hline 2010 & Colicchia et al [25] & & $\mathrm{X}$ & $X$ & & $\mathrm{X}$ & $X$ & & $\mathrm{SC}$ \\
\hline 2010 & Pettit et al. [26] & $X$ & $\mathrm{X}$ & $\mathrm{X}$ & & $\mathrm{X}$ & $\mathrm{X}$ & & $\mathrm{BC}, \mathrm{SC}$ \\
\hline 2011 & $\begin{array}{l}\text { Carvalho \& Cruz- } \\
\text { Machado [16] }\end{array}$ & & $X$ & $X$ & & $X$ & $X$ & & $\mathrm{SC}$ \\
\hline 2011 & Jüttner \& Maklan [27] & X & $X$ & $X$ & & $X$ & $\mathrm{X}$ & & $\mathrm{SC}$ \\
\hline 2011 & Ismail et al. * [28] & $\mathrm{X}$ & $\mathrm{X}$ & $\mathrm{X}$ & $\mathrm{X}$ & $\mathrm{X}$ & $\mathrm{X}$ & $\mathrm{X}$ & $\mathrm{SO}$ \\
\hline
\end{tabular}


Adapt/reconfigure. This aspect marks the beginning of feeling some real pressure and initial effects. Depending on decision preferences and available capabilities built, the firm attempts to respond. Firms may need different (multiple) forms of agility features to reconfigure the what, how and when they do in responding to unanticipated changes. While adaptive capabilities do not exclude responses to enhance opportunities, majority of the literature reviewed considers threats and disruptions only (conf. table 1).

Sustain. The essence of adapting/reconfiguring is sustaining the meeting of business objectives (i.e. delivery function). Continuing to perform one way or another is an important feature that reduces unwanted long term consequences which may happen if the firm discontinues functioning and recover back after sometime (e.g. [8]).

Recover/enhance. This aspect is about re-attaining competitive performance levels once the effects of shocks or pressures are felt. Recover is mainly concerned with disruptive events (conf. disruption profile in [1]). For operational resilience it is important that firms try to enhance and realize potential gains from opportunity events which otherwise may become threats (e.g. [19]).

Another way of looking at these features is from time horizon viewpoint. Sense and build focus on firms' capabilities of utilizing and rearranging strategic assets before an unwanted change event happens. They are also referred to as preparedness. Adapt/reconfigure and sustain reflect on capabilities and actions during the course of the unwanted change prevalence. Readers may refer to details of the Dell example mentioned before [3] to see how the company performed in these phases. Recover/enhance, as the name implies, has to do with efforts to bring a performance level that is better from long term perspective in relation to some reference. It is not guaranteed that the reference performance measure and level remain the same as they were before the encounter. The operational resilience towards pressure/change circumstances can also be viewed based on nature of the circumstances with regard to continuity and intensity of happenings (i.e. typologies like transient, cyclic, long-lasting, etc) which needs further investigation in itself.

To meet our objective of consistent and comprehensive operational resilience definition, we have tried to concentrate on the core aspects identified from extant literature while trying to avoid dependence on indicative mechanisms since specific capabilities depend on prevailing circumstances, industry and other firm related variables in addition to selective arrangement of capabilities being what makes resilience a source of competitive advantage. We, therefore, state that operational resilience is the inherent (integrative) capability of an enterprise at different management levels and business units to defy unanticipated pressure (threats and opportunities) coming from internal and external causes, to persist on guaranteeing the efficient achievement of objectives and targets before, during, and after encounter of the pressure.

\subsection{Further Insight on Operational Resilience Features}

In essence, operational resilience integrates the different resilience perspectives in business firms. Supply chain operations of plan, source, make, deliver (and return) can be less prone to unwanted influences of pressures from within (internal focus) or from outside (customers, suppliers, competitors, or other stakeholders) to operationally perform better for improved and consistent achievement of objectives. 
Our understanding from literature is that conceptual contributions on operationally resilience in business firms can be outlined as follows (conf. Table 1 last column).

1. From supply chain risk and resilience management perspective;

2. From emergent strategic management organizational perspective;

3. From business functioning, continuity and crisis management view; and

4. As a way to fulfil governance and control requirements.

The number of publications corresponding to these resilience perspectives shown in table 1 , in respective order as the above list, are: 14, 6, 3 and 2.

The literature on supply chain resilience concentrate on resilience aspects that are related to velocity, flexibility, visibility, and collaboration [7], [27]. Organizational resilience literature mainly is concerned with learning and dynamism in humans as collective decision makers (cognitive and behavioural aspects). When resilience is viewed from strategic perspectives reconfigurations and enforcing changes before changes force a firm unwillingly change something at higher expenses [19], [17]. Governance related resilience literature dealt mainly with issues of compliance, control, mandate and commitment (e. g. [18]). When managed in an integrative manner with the other perspectives, it contributes to building leverages. Sustaining continuous fulfilment of objectives mainly emanates from business continuity viewpoint [21]. These perspectives in integration provide a broader view of operational resilience.

\subsection{Operationalization of the Resilience Concept}

Even though some inconsistencies in conceptualization exist, several conceptual models and frameworks have been developed. Scholars have also tried to devise ways on how resilience is practically implemented and measured. Attempts include creating a balance between capability building efforts and vulnerability levels [26]. Regardless of the attempts on measuring business value of building operational resilience capabilities, quantifying the gains of resilience capability building investment against other alternative or opportunity costs still remains challenging. Some scholars (e.g. [16]) tried to compare resilience with other paradigms qualitatively, others (e.g. [22]) tried to measure resilience based on supply chain network features but only considering the downside o risk.

In a very structured form of risk management a typical procedure would be to identify risk events as exhaustively as possible, analyzing their likelihood of occurrence, and potential selective response mechanisms (e.g. [2], [29]). A limitation to this widely used approach is revealed as and when uncertainties and risk event counts dramatically increase, impairing soundness of managerial decisions. Argued benefit of pursuing operational resilience conception with dynamic capabilities is that building higher order capabilities that entail agility in terms multifaceted [7] applications helps to generate lower level capabilities suited to run operations under the prevailing circumstances. So, the need to make extensive analysis of every possible risk factors and consequences can be reduced. We also recall that the operational resilience definition adopted here implies cost conscious thinking because whatever investment we make and however we do it has implications to stakeholders, including customers. 


\section{Conclusion}

The state-of-the-art review of literature reveals that the inconsistencies in conceptualizing and defining resilience can be narrowed down by identifying relevant aspects and reconstructing a definition. In addition to concepts the review has also tried to indicate interesting gaps that could lead to possible future research. In resilience literature maintaining redundancy of strategic assets is dominant which in lean thinking paradigm were needed to be minimized to reduce non-value adding costs (wastes), and boosting efficiencies. Does this imply that operational resilience is essentially against the principles and implementation practices of lean thinking? Several scholars claim that lean thinking is suitable for stable (not turbulent) business environment. On the other hand, some global companies following lean strategy showed better performance than their competitors amid a common dynamic unfavourable circumstance. Could there be scientific explanation? Could there be some 'better capability' of the companies in utilizing some principles and tools that enable them to practice lean and resilience features together? How do operational resilience features improve competitive advantages? Such questions need a detailed study for justified answers with future research.

Acknowledgement. This paper has been produced as part of the EDIM Joint Doctoral Programme between POLIMI, KTH, and UPM funded by EACEA (EC) under the EMJD Programme.

\section{References}

1. Sheffi, Y., Rice, J.B.: A supply chain view of the resilient enterprise. MIT Sloan Management Review 47, 41-48 (2005)

2. Christopher, M., Peck, H.: Building the resilient supply chain. International Journal of Logistics Management 15, 1-13 (2004)

3. Breen, B.: Living in Dell time, Fastcompany, New York (November 2004)

4. Sheffi, Y.: The resilient enterprise: overcoming vulnerability for competitive advantage. MIT Press, London (2007)

5. Ponomarov, S.Y., Holcomb, M.C.: Understanding the concept of supply chain resilience. The International Journal of Logistics Management 20, 124-143 (2009)

6. Walker, B.H., Holling, C.S., Carpenter, S.R., Kinzig, A.: Resilience, adaptability and transformability in social - ecological systems. Ecology and Society 9, 5 (2004)

7. Oh, L.-B., Teo, H.-H.: The impacts of information technology and managerial proactiveness in building net-enabled organizational resilience. In: Donnellan, T.J., Larsen, L., Levine, J.I. (eds.) The Transfer and Diffusion of Information Technology for Organizational Resilience. IFIP, vol. 206, pp. 33-50. Springer, Boston (2006)

8. McManus, S.T., Seville, E., Brunsdon, D., Vargo, J.: Resilience management: A framework for assessing and improving the resilience of organisations (2007)

9. Rose, A.: Economic resilience to natural and man-made disasters: Multidisciplinary origins and contextual dimensions. Environmental Hazards 7, 383-398 (2007)

10. Waters, D.: Supply chain risk management: vulnerability and resilience for logistics. Kogan-Page, London (2007)

11. Scholz, R.W., Blumer, Y.B., Brand, F.S.: Risk, vulnerability, robustness, and resilience from a decision-theoretic perspective. Journal of Risk Research 15, 3133-3330 (2012)

12. Bhamra, R., Dani, S., Burnard, K.: Resilience: the concept, a literature review and future directions. International Journal of Production Research 49, 5375-5393 (2011) 
13. Vugrin, E.D., Warren, D.E., Ehlen, M.A., Camphouse, R.C.: A framework for assessing the resilience of infrastructure and economic systems. In: Gopalakrishnan, K., Peeta, S. (eds.) Sustainable and Resilient Critical Infrastructure, pp. 77-116. Springer-Verlag B-H (2010)

14. Fiksel, J.: Designing resilient, sustainable systems. Environmental Science \& Technology $37,5330-5339$ (2003)

15. Holling, C.S.: Resilience and sustainability of ecological systems. Annual Review of Ecology and Systematics 4, 1-23 (1973)

16. Carvalho, H., Cruz-Machado, V.: Integrating lean, agile, resilience and green paradigms in supply chain management (LARG_SCM ). In: Li, P. (ed.) Supply Chain Management, pp. 27-48. InTech, New Delhi (2011)

17. Välikangas, L.: The resilient organization: how adaptive cultures thrive even when strategy fails. McGraw-Hill (2010)

18. Frost, C., Allen, D., Porter, J., Bloodworth, P.: Operational risk and resilience: understanding and minimizing operational risk to secure shareholder value. Elsevier (2000)

19. Hamel, G., Välikangas, L.: The quest for resilience (2003)

20. Craighead, C.W., Blackhurst, J., Rungtusanatham, M.J., Handfield, R.B.: The severity of supply chain disruptions: design characteristics and mitigation capabilities. Decision Sciences 38, 131-156 (2007)

21. Caralli, R.A.: Sustaining operational resiliency: A process improvement approach to security management (2006)

22. Falasca, M., Zobel, C.W., Cook, D.: A decision support framework to assess supply chain resilience. In: Fiedrich, F., de Walle, B.V. (eds.) Proceedings of the 5th International ISCRAM Conference, Washington DC, USA, pp. 596-605 (2008)

23. Stolker, R.J.M., Karydas, D.M., Rouvroye, J.L.: A comprehensive approach to assess operational resilience. In: Hollnagel, E., Pieri, F. (eds.) Proceedings of the 3rd Resilience Engineering Symposium, Antibes-Juan-les-Pins, France, pp. 247-253 (2008)

24. Melnyk, S.A., Davis, E.W., Spekman, R.E., Sandor, J.: Outcome-driven supply chains. MIT Sloan Management Review 51, 33-38 (2010)

25. Colicchia, C., Dallari, F., Melacini, M.: Increasing supply chain resilience in a global sourcing context. Production Planning \& Control 21, 680-694 (2010)

26. Pettit, T.J., Fiksel, J., Croxton, K.L.: Ensuring Supply Chain Resilience: Development of a Conceptual Framework. Journal of Business Logistics 31, 1-22 (2010)

27. Jüttner, U., Maklan, S.: Supply chain resilience in the global financial crisis: an empirical study. Supply Chain Management: An International Journal 16, 246-259 (2011)

28. Ismail, H.S., Poolton, J., Sharifi, H.: The role of agile strategic capabilities in achieving resilience in manufacturing-based small companies. International Journal of Production Research 49, 5469-5487 (2011)

29. ISO: ISO 31000 Risk management — Principles and guidelines (2009)

\section{Appendix: Literature Search Keywords}

These are the list of keywords used in literature search: risk AND resilience; (enterprise OR organization OR operation OR "supply chain") AND resilience; (vulnerability OR disruption OR uncertainty OR adaptability OR recovery OR agility OR flexibility OR mitigation OR crisis OR disaster) AND resilience; (resilience OR risk OR “business continuity”) AND (management OR analysis OR assessment). 